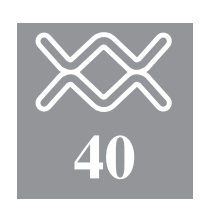

\title{
Trattamento dei pazienti dializzati con infezione da $\mathrm{HCV}$
}

\author{
A. Grimaldi', P. Di Cocco², C. Mazzotta'2, V. Rizza², M. D'Angelo², L. Bonanni², \\ K. Clemente ${ }^{2}$, C. Laurenzi ${ }^{2}$, A. Famulari², F. Pisani² \\ ${ }^{1}$ U.O. di Malattie Infettive e Tropicali \\ ${ }^{2}$ U.O. Trapianti d'Organo, Ospedale Regionale "San Salvatore", L'Aquila
}

$\mathbf{L}$ a positività per $\mathrm{HCV}$, nel paziente in lista di attesa per trapianto di rene, rappresenta una problematica ancora discussa poiché non esistono, attualmente, parametri ematochimici e virologici in grado di definire correttamente il rischio post-trapianto di progressione della malattia virale.

Il protocollo infettivologico pre-trapianto che il Centro Trapianti di L'Aquila ha adottato nei pazienti con infezione da virus dell'epatite $\mathrm{C}$ si basa sulla somministrazione di Interferone alfa leucocitario (6 milioni di U.I. tre volte la settimana) per la durata di 48 settimane nei pazienti portatori di $\mathrm{HCV}$ (genotipo $1 \mathrm{~b}$ ).

I pazienti con positività anticorpale nei confronti dell'HCV vengono sottoposti a ulteriori esami ematochimici per la valutazione della funzionalità epatica (AST, ALT, GGT, fosfatasi alcalina, bi- lirubina totale e frazionata), della replicazione virale (HCV-RNA PCR con metodica sia qualitativa che quantitativa) e del genotipo virale.

La carica virale, da sola, rappresenta una controindicazione al trapianto per cui i pazienti vengono inseriti in lista "attiva" nel momento in cui viene negativizzata (HCV-RNA PCR pari a zero); ad oggi, presso il nostro Centro, questi pazienti non vengono sottoposti a valutazione istologica del grado di epatopatia.

Sono stati sottoposti a trattamento antivirale 10 pazienti, in trattamento emodialitico sostitutivo, con infezione da virus dell'epatite $C$ (genotipo $1 \mathrm{~b}$ ), di cui 9 con livelli di transaminasi normali e 1 con transaminasi elevate; tutti con HCV-RNA dosabile nel siero.

Tutti i pazienti hanno risposto in modo ottimale al trattamento presentando una negativizzazione della carica virale entro il terzo mese dall'inizio del trattamento. Tra gli effetti collaterali più importanti della terapia abbiamo riscontrato: febbre (70\%); artralgie (50\%); piastrinopenia e leucopenia (20\%).

La terapia condotta per 48 settimane è stata seguita nei sei mesi successivi all'interruzione da un "relapse" della carica virale per tutti i pazienti.

Nella nostra esperienza la terapia con il solo interferone, pur dando risultati molto incoraggianti durante il trattamento, ha comportato un elevato tasso di insuccesso. Pertanto, confortati dalla letteratura, stiamo intraprendendo un protocollo terapeutico che prevede la somministrazione di PEG-INF (135 mcg una volta la settimana) e Ribavirina (200-400 mg/die), dopo aver sottoposto tutti i pazienti con epatite $\mathrm{C}$ cronica, positivi per HCV-RNA, a biopsie epatiche eco-guidate (vedi Schema di trattamento). 


\section{SCHEMA DI TRATTAMENTO PZ DIALIZZATI CON EPATITE C}

PAZIENTI HCV-PCR POSITIVI con aumento delle TRANSAMINASI*:

A) PEG-INTERFERONE (PEGASYS), $135 \mathrm{mg} \mathrm{fl}: 1 \mathrm{fl} \mathrm{sc} / \mathrm{sett}$;

B) RIBAVIRINA, $200 \mathrm{mg}$ cp: 1 cp/die.

(tale dosaggio può essere aumentato se ben tollerato)

* Stretto monitoraggio: - eventuale anemie

- eventuale leucopenia

eritropoietina; granulokine (GM-CSF).

Durata trattamento: $\quad-6$ mesi per i genotipi 2 e 3;

- 12 mesi per i genotipi 1 e 4.

N.B. Le condizioni fondamentali per la prosecuzione della terapia sono rappresentate dall'assenza di effetti collaterali gravi e dalla NEGATIVIZZAZIONE dell' HCV-RNA qualitativo entro il terzo mese di trattamento.

2) PAZIENTI HCV-PCR POSITIVI con normali livelli delle TRANSAMINASI*:

A) PEG-INTERFERONE (PEGASYS), $135 \mathrm{mg} \mathrm{fl:} 1 \mathrm{fl} \mathrm{sc/sett;}$

B) RIBAVIRINA, $200 \mathrm{mg}$ cp: $1 \mathrm{cp} /$ die.

(tale dosaggio può essere aumentato se ben tollerato)

* Stretto monitoraggio: - eventuale anemia - eventuale leucopenia eritropoietina; granulokine (GM-CSF).

Durata trattamento: $\quad-6$ mesi per i genotipi 2 e 3;

- 12 mesi per i genotipi 1.

N.B. Le condizioni fondamentali per la prosecuzione della terapia sono rappresentate dall'assenza di effetti collaterali gravi (quali anemia e leucopenia che non rispondono al trattamento) e dalla NEGATIVIZZAZIONE dell' HCV-RNA qualitativo entro il terzo mese di trattamento. 